\title{
Intake of Carp Meat From Two Aquaculture Production Systems Aimed at Secondary Prevention of Ischemic Heart Disease - a Follow-up Study
}

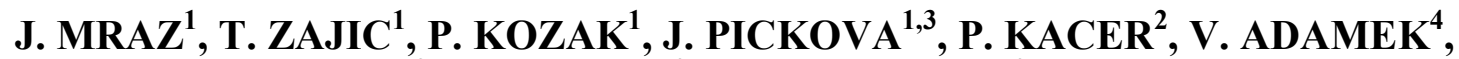 \\ I. KRALOVA LESNA ${ }^{2}$, V. LANSKA ${ }^{2}$, V. ADAMKOVA ${ }^{2}$
}

${ }^{1}$ South Bohemian Research Center of Aquaculture and Biodiversity of Hydrocenoses, Institute of Aquaculture and Protection of Waters, Faculty of Fisheries and Protection of Waters, University of South Bohemia in Ceske Budejovice, Ceske Budejovice, Czech Republic, ${ }^{2}$ Institute for Clinical and Experimental Medicine, Prague, Czech Republic, ${ }^{3}$ Department of Food Science, Swedish University of Agricultural Sciences, Uppsala, Sweden, ${ }^{4}$ Faculty of Biomedical Engineering, Czech Technical University, Kladno, Czech Republic

Received November 1, 2016

Accepted December 22, 2016

\section{Summary}

Our previous study showed that a diet enriched with $400 \mathrm{~g}$ of carp per week improved plasma lipids in subjects after aortocoronary bypass (CABG). The aim of the present study is to determine whether the different carp farming systems have an impact on the effects of carp meat in secondary cardiovascular prevention. We examined 3 groups of patients after CABG over a 4-week period of spa treatment (108 persons, 73 males, 35 females, age over 60 years). We found no differences in baseline values of blood pressure or plasma lipids. The patients were given a standard spa diet (controls; $\mathrm{N}=36$ ) or a diet enriched of $400 \mathrm{~g}$ of carp meat per week, enriched omega-3 $(\mathrm{N}=37)$ or cereal carp $(\mathrm{N}=35)$. Plasma lipid parameters were examined at start and after 4 weeks in a routine laboratory setting. Group consuming omega-3 carp showed the largest decline in total cholesterol, LDL cholesterol, triglycerides and an increase in HDL cholesterol (all $\mathrm{p}<0.01$ ). We found that carp meat from the two production systems showed significantly different effects on plasma lipids. Further trials should be performed to clarify the exact causes of the differences.

\section{Key words}

Cardiovascular health • Carp • Fish oil • n-3 PUFA • Nutrition

\section{Corresponding author}

V. Adamkova, Institute for Clinical and Experimental Medicine, Videnska 1958/9, Prague 4, Czech Republic. Fax: +420261710666. E-mail: vead@ikem.cz

\section{Introduction}

Fish intake has been associated with lower risk of total and cardiovascular disease mortality in many, but not all studies (Villegas et al. 2015). Most of the health benefits of fish consumption are usually attributed to the high content of omega-3 long-chain polyunsaturated fatty acids (n-3 LC PUFA), especially eicosapentaenoic (EPA) and docosahexaenoic acid (DHA), of which fish is the major dietary source (Balk et al. 2006). Animal and human studies have demonstrated that n-3 LC PUFAs improve the function of the normal and damaged endothelium, by an increasing nitric oxide availability and the metabolic pathways of cytochrome P450 epoxygenases. These epoxides cause potent vasodilatation and blood pressure reduction. Additionally, the antioxidant, anti-inflammatory, and anti-thrombotic properties of omega-3 fatty acids improve the stabilization of the electrophysiological properties of cardiomyocytes (Colussi et al. 2017). Most health authorities recommend two servings of fish per week as part of a healthy balanced diet. The European 
Food Safety Authority (EFSA) Scientific Panel on Contaminants in the Food Chain state: "There is evidence that fish consumption, especially of fatty fish (one to two servings a week) benefits the cardiovascular system and is suitable for secondary prevention in manifested coronary heart disease" (EFSA 2005). The EFSA Panel on Dietetic Products, Nutrition and Allergies has set the following Adequate Intake values: linoleic acid (LA) $4 \mathrm{E} \%$ (percentage of total dietary energy per day), alpha linolenic acid (ALA) $0.5 \mathrm{E} \%$; EPA+DHA, adults $250 \mathrm{mg}$; DHA, children 6-24 months $100 \mathrm{mg}$; pregnancy and lactation, an additional $100-200 \mathrm{mg}$ of DHA (EFSA 2010).

Despite recommendations, fish consumption in Central Europe remains very low, e.g. in the Czech Republic it amounts to only $5.5 \mathrm{~kg}$ of fish and fish products per capita per year (Zeniskova and Gall 2009, ÚZEI 2016). Compared to marine fish, freshwater fish which usually contain a lower content of n-3 LC PUFA, are often overlooked as a source (Ackman 2002). Most observation studies and clinical trials have been realized using marine fish or fish oil, but not many articles related to freshwater fish and cardiovascular health are available. Fish also contains other potentially important nutrients such as taurine, selenium and astaxanthin which are understood to displace less healthy components in the diet (Radcliffe et al. 2016). In the Lugalawa study, Pauletto et al. (1996) compared a group of Tanzanian villagers on a high fish consumption diet (300-600 g daily) with a group on a vegetarian diet. The fish eaters were found to have significantly lower blood pressure and plasma lipid concentrations.

In our previous study (Adamkova et al. 2011) we showed that a diet enriched with 2 meals of carp (200 g each portion) per week significantly improved plasma lipids and markers of inflammation (high-sensitive CRP) in the blood of subjects after cardiac revascularization surgery for ischemic heart disease over a four-week period of follow-up spa treatment. The carp meat used in the study had a relatively low amount of n-3 LC PUFA in relation to the high effects observed on plasma lipid parameters, which led us to the hypothesis that it may not have been just lipid quality that was responsible for the effects observed.

Moreover, carp meat fat content and fatty acid composition are highly variable (Mraz and Pickova 2011) and influenced by farming systems (Mraz et al. 2012a), nutrition (Mraz et al. 2012b), purging (Zajic et al. 2013), processing (Sampels et al. 2015), cooking (Sampels et al.
2014) and other factors. Recently, a patented system (Mraz et al. 2011) for the aquaculture production of "omega-3 carp" (carp with increased content of n-3 FA) was developed and successfully tested. This type of omega-3 carp is already available on the market in the Czech Republic and sold under a specific trademark (Fig. 1). However, so far no study has compared the effects of carp meat from different production systems (cereal supplementation $\mathrm{x}$ pelleted feed) on cardiovascular prevention.

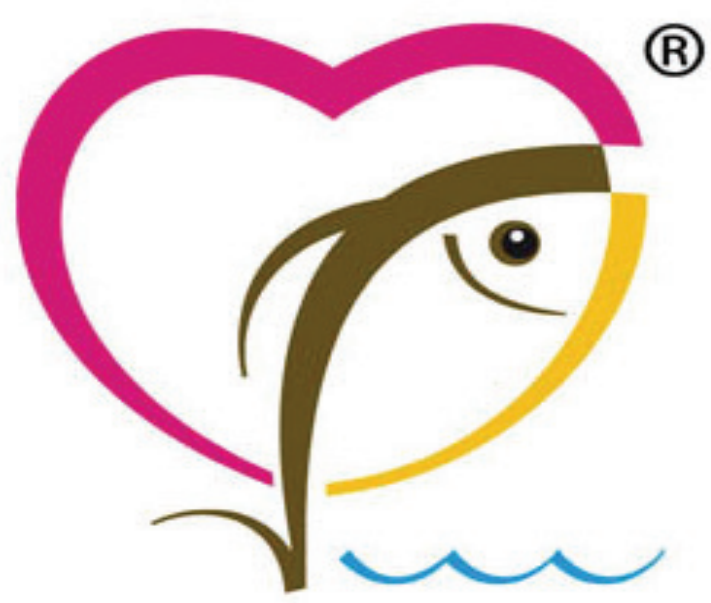

Fig. 1. Commercial trademark used in the Czech Republic for omega-3 carp (carp with increased content of n-3 FA).

Therefore, the aim of the present study was to confirm the results from our previous trial (Adamkova et al. 2011) and to examine whether carp farming systems would have an impact on carp meat health effects as a means towards post-surgery secondary cardiovascular prevention.

\section{Methods}

\section{Carps production}

The carps used for the intervention study were raised under two different pond production systems by the company Blatenská ryba, s.r.o. (i.e. Blatná Fish, Ltd., South Bohemian Region, Czech Republic). The first group was cultured with a traditional pond culture using supplemental cereal feeding (cereal carp). The other group was produced using the company's patented technology (Mraz et al. 2011) of pond production of carp with increased content of n-3 fatty acids (omega-3 carp). Both groups were cultured in earthen dam fish ponds (2-3 ha) during the period April-September, 2010, 
(stocked with 3-year-old carps with an average weight of $1 \mathrm{~kg}$; stocking density 670 individuals/ha) and supplemented three times a week with either triticale (Triticosecale) (cereal carp) or special feed KP Len (Výroba krmiv, s.r.o., Strríbrné hory, Czech Republic) containing $12 \%$ rapeseed cake and $20 \%$ extruded linseed (omega-3 carp). Fish were harvested in September (with an average weight of $2.3 \mathrm{~kg}$ ), purged in small purging ponds for 14 days, filleted, vacuum packed, frozen and delivered to Spa Poděbrady (Czech Republic) for the intervention study.

Ten fillets per group were randomly selected for chemical analysis of carp meat quality. Lipid content and fatty acid composition of carp fillets were analyzed as described in Mraz and Pickova (2009). Briefly, carp fillets were homogenized and $1 \mathrm{~g}$ of the aliquot sample used for lipid extraction using the hexane/isopropanol method (Hara and Radin 1978). Fatty acids were methylated (Appelqvist 1968) and analyzed by gas chromatography (Fredriksson Eriksson and Pickova 2007). Fatty acids were identified by comparison using the standard mixture GLC-68A (Nu-Check Prep, Elysian, $\mathrm{MN}$ ) and retention times. For calculating the absolute amount of individual fatty acids, an internal standard of 15-methylheptadecanoate (Larodan Fine Chemicals AB, Malmö, Sweden) was used.

\section{Intervention study}

One hundred and eight patients after aortocoronary bypass in secondary prevention were included. None of these patients smoked during treatment (spa treatment after aortocoronary bypass) and none of the patients enrolled into this study had prescribed a special diet. The patients with verified diabetes mellitus type 2 were excluded. All were medicated with statins, beta-blockers and acetylsalicylic acid by their ambulatory cardiologists. The post-surgery patients underwent recovery for four weeks in the Spa Poděbrady (Czech Republic). During spa treatment, the patients consumed a standard spa diet for patients after cardiac surgery (controls) or a standard diet enriched with meals prepared from $2 \times 200 \mathrm{~g}$ of carp meat per week using either "omega-3 carp" or "cereal carp". There were no differences in baseline values among the three groups (sex, age, blood pressure, lipid parameters, heart rate and body mass index) (Table 2). Laboratory tests for lipid parameters were performed at the start and at the end of the period. Total cholesterol and triglycerides were determined in fasting blood samples using an enzymatic method (Hoffmann-La Roche, Switzerland). High-density lipoprotein cholesterol concentrations were analyzed (Cobas Mira Plus, Roche, Switzerland) after precipitation of apolipoprotein B-containing particles using the phosphotungstate method. Low density lipoprotein cholesterol (LDL-C) was measured by a direct method using a commercially available kit (Roche Diagnostics, Basel, Switzerland). Blood pressure measurements were taken on the right forearm in the sitting position after at least ten minutes of rest. Three blood pressure readings were obtained, and the mean value of the final last two measurements was used for further analysis.

\section{Statistical analysis}

Data were analyzed using the paired t-test, the two-sample t-test, ANOVA and multivariate linear regression analysis. All data are expressed as means \pm standard deviations. A $p$-level $<0.05$ was considered statistically significant. Statistical analyses were performed without regard to gender, because of our previous studies we know that gender played no role in influencing these monitored parameters.

\section{Results}

\section{Carp meat analyses}

The carp used in the intervention study had a very distinct meat quality (Table 1). Analysis revealed significantly higher amounts of PUFA and n-3 LC PUFA in omega-3 carp meat, while the cereal carp meat contained a higher proportion of MUFA (mostly oleic acid; 18:1n-9). Moreover, omega-3 carp had a content of beneficial EPA+DHA five times higher than that of cereal carp (53 vs. $262 \mathrm{mg}$ of EPA+DHA per $100 \mathrm{~g}$ fillet).

\section{Intervention study}

The basic parameters of the study probands at the start of this trial are shown in Table 2.

Changes in the plasma lipid profiles of subjects after 4 weeks of intervention are shown in Table 3. The best results were found in group consuming omega-3 carp, which recorded the highest HDL cholesterol values and the largest decline in total cholesterol, LDL-C and triglycerides. We found no differences in fasting glucose, systolic/diastolic blood pressure or body mass index after spa treatment among the three groups. The lipid parameters after 4 weeks spa-treatment are shown in Table 4.

Five years after the surgery events, all subjects were reassessed using questionnaire survey. Thirty-one 
persons responded from group consuming omega-3 carp, 29 from group consuming cereal carp and only 2 from control group. There were no cases of myocardial infarction. In the intervening 5 years, 4 people from groups consuming carps were hospitalized for deteriorated blood pressure. All patients attended regular check-ups. Twenty eight individuals continued to consume $200 \mathrm{~g}$ of freshwater fish twice a week.

Table 1. Fillet lipid content and fatty acid composition (\% and $\mathrm{mg} / 100 \mathrm{~g})$ of cereal supplemented and omega-3 carp used for the intervention (mean $\pm S D ; n=6$ ).

\begin{tabular}{|c|c|c|c|c|}
\hline & $\begin{array}{c}\text { Cereal carp } \\
\%\end{array}$ & $\begin{array}{c}\text { Omega-3 carp } \\
\%\end{array}$ & $\begin{array}{l}\text { Cereal carp } \\
\mathrm{mg} / \mathbf{1 0 0} \mathrm{g}\end{array}$ & $\begin{array}{c}\text { Omega-3 carp } \\
\mathrm{mg} / \mathbf{1 0 0} \mathrm{g}\end{array}$ \\
\hline Lipids & $6.8 \pm 2.1$ & $6.2 \pm 2.0$ & $6788 \pm 2057$ & $6197 \pm 1974$ \\
\hline $14: 0$ & $1.1 \pm 0.1$ & $1.4 \pm 0.3 * *$ & $63 \pm 17$ & $73 \pm 23$ \\
\hline $15: 0$ & $0.1 \pm 0.1$ & $0.3 \pm 0.2 * * *$ & $4 \pm 3$ & $15 \pm 6^{* *}$ \\
\hline $16: 0$ & $19.4 \pm 1.1$ & $18.5 \pm 1.1$ & $1128 \pm 326$ & $975 \pm 300$ \\
\hline $18: 0$ & $6.5 \pm 0.6$ & $4.8 \pm 0.8^{* *}$ & $373 \pm 105$ & $254 \pm 83$ \\
\hline $16: 1 n-7$ & $9.5 \pm 1.8$ & $9.3 \pm 1.1$ & $569 \pm 210$ & $496 \pm 172$ \\
\hline $18: \ln -9$ & $48.5 \pm 2.8$ & $32.3 \pm 8 * *$ & $2805 \pm 819$ & $1757 \pm 650^{*}$ \\
\hline $18: 1 n-7$ & $3.4 \pm 0.2$ & $3.7 \pm 0.3$ & $197 \pm 56$ & $195 \pm 60$ \\
\hline $20: 1 n-9$ & $1.6 \pm 0.3$ & $1.7 \pm 0.3$ & $91 \pm 17$ & $92 \pm 33$ \\
\hline $18: 2 n-6$ & $5.7 \pm 0.6$ & $11.8 \pm 1.1^{* * *}$ & $317 \pm 63$ & $622 \pm 189 * *$ \\
\hline $20: 2 n-6$ & $0.2 \pm 0.1$ & $0.3 \pm 0.1$ & $9 \pm 4$ & $15 \pm 5$ \\
\hline $20: 3 n-6$ & $0.2 \pm 0.1$ & $0.3 \pm 0.0^{* *}$ & $11 \pm 1$ & $16 \pm 4^{*}$ \\
\hline $20: 4 n-6$ & $0.7 \pm 0.3$ & $1.3 \pm 0.5^{*}$ & $38 \pm 10$ & $66 \pm 17^{* *}$ \\
\hline $18: 3 n-3$ & $0.9 \pm 0.2$ & $5.2 \pm 1.7 * * *$ & $50 \pm 18$ & $262 \pm 92 * * *$ \\
\hline $18: 4 n-3$ & $0.6 \pm 0.1$ & $1.3 \pm 0.5^{*}$ & $36 \pm 11$ & $66 \pm 32$ \\
\hline $20: 5 n-3$ & $0.4 \pm 0.2$ & $3.2 \pm 1.7^{* *}$ & $20 \pm 11$ & $152 \pm 58 * * *$ \\
\hline $22: 5 n-3$ & $0.3 \pm 0.1$ & $1.0 \pm 0.5^{* *}$ & $14 \pm 4$ & $48 \pm 16^{* * *}$ \\
\hline $22: 6 n-3$ & $0.6 \pm 0.2$ & $2.4 \pm 1.5^{*}$ & $34 \pm 4$ & $110 \pm 35^{* * *}$ \\
\hline$S F A$ & $27.1 \pm 0.8$ & $25.4 \pm 1.0^{*}$ & $1568 \pm 439$ & $1338 \pm 401$ \\
\hline MUFA & $63.3 \pm 1.7$ & $47.3 \pm 7.1 * * *$ & $3667 \pm 1074$ & $2554 \pm 860$ \\
\hline PUFA & $9.6 \pm 1.4$ & $27.3 \pm 6.4^{* * *}$ & $534 \pm 99$ & $1375 \pm 389 * * *$ \\
\hline$n-6$ & $6.9 \pm 1.0$ & $139 \pm 1.2 * * *$ & $381 \pm 66$ & $726 \pm 210^{* *}$ \\
\hline$n-3$ & $2.7 \pm 0.5$ & $13.4 \pm 5.8^{* *}$ & $153 \pm 40$ & $649 \pm 231 * * *$ \\
\hline$n-3$ LC PUFA & $1.3 \pm 0.4$ & $6.9 \pm 3.8^{* *}$ & $67 \pm 17$ & $322 \pm 115^{* * *}$ \\
\hline$E P A+D H A$ & $1.0 \pm 0.3$ & $5.6 \pm 3.1^{* *}$ & $53 \pm 13$ & $262 \pm 91 * * *$ \\
\hline
\end{tabular}

SFA, saturated fatty acids; MUFA, monounsaturated fatty acids; PUFA, polyunsaturated fatty acids; LC PUFA, long chain polyunsaturated fatty acids (20 and more carbons); EPA, eicosapentaenoic acid (20:5n-3); DHA, docosahexaenoic acid (22:6n-3); $*, * *, * * *$ - statistically significant difference between the two groups at $p<0.05 ; p<0.01 ; p<0.001$, respectively, independent two-sample Student's t-test.

\section{Discussion}

To our best knowledge, our study is the first work aimed at investigating the impact of common carp farming systems on secondary cardiovascular prevention effects.

The results show that consumption of common carp meat with increased content of n-3 LC PUFA has positive effects on plasma lipids in subjects recovering from heart surgery. Therefore, it indicates that carp consumption would be beneficial in general. Fish consumption is generally very low in the Czech Republic (Zeniskova and Gall 2009, ÚZEI 2016) and far below current recommendations. This suggests that it would be beneficial to boost fish consumption in general as well as to increase the content of beneficial fatty acids in locally produced fish and associated products. 
Table 2. Basic proband parameters at beginning of the study.

\begin{tabular}{|c|c|c|c|c|}
\hline & Omega-3 carp group & Cereal carp group & Controls & $\mathbf{p}$ \\
\hline$N$ & 37 & 35 & 36 & \\
\hline Males/females & 26/11 & $25 / 10$ & $22 / 14$ & \\
\hline$T C(\mathrm{mmol} / \mathrm{l})$ & $5.2 \pm 0.43$ & $5.0 \pm 0.69$ & $5.2 \pm 0.61$ & n.s. \\
\hline$L D L-C(\mathrm{mmol} / \mathrm{l})$ & $2.7 \pm 0.46$ & $2.6 \pm 0.88$ & $2.5 \pm 0.53$ & n.s. \\
\hline$H D L-C(\mathrm{mmol} / \mathrm{l})$ & $0.9 \pm 0.21$ & $0.8 \pm 0.20$ & $0.9 \pm 0.22$ & n.s. \\
\hline$T G(\mathrm{mmol} / \mathrm{l})$ & $2.0 \pm 0.57$ & $2.0 \pm 0.65$ & $1.7 \pm 0.51$ & n.s. \\
\hline Glucose (mmol/l) & $6.1 \pm 0.95$ & $6.1 \pm 0.78$ & $6.1 \pm 0.97$ & n.s \\
\hline $\mathrm{SBP}(\mathrm{mm} \mathrm{Hg})$ & $129.1 \pm 10.36$ & $130.2 \pm 9.84$ & $130.8 \pm 7.65$ & n.s. \\
\hline$D B P(m m ~ H g)$ & $80.3 \pm 4.26$ & $81.1 \pm 4.98$ & $83.2 \pm 6.49$ & n.s. \\
\hline$H R$ (min) & $70.3 \pm 4.67$ & $69.9 \pm 4.92$ & $70.4 \pm 5.02$ & n.s. \\
\hline$B M I\left(\mathrm{~kg} / \mathrm{m}^{2}\right)$ & $27.5 \pm 6.38$ & $27.6 \pm 7.01$ & $28.0 \pm 7.92$ & n.s. \\
\hline
\end{tabular}

Controls - standard spa diet for patients after cardiac surgery; cereal carp group - standard diet enriched by cereal carp; omega-3 carp group - standard diet enriched by omega-3 carp. TC, total cholesterol; LDL-C, low density cholesterol; HDL-C, high density cholesterol; TG, triglycerides; SBP, systolic blood pressure; DBP, diastolic blood pressure; HR, heart rate; BMI, body mass index.

Table 3. Plasma lipid changes in three studied groups of patients after 4 weeks of dietary intervention.

\begin{tabular}{lccc}
\hline & Omega-3 carp group & Cereal carp group & Controls \\
\hline$N$ & 37 & 35 & 36 \\
Total $C(\mathrm{mmol} / \mathrm{l})$ & $-1.3 \pm 0.75^{* * *}$ & $-0.2 \pm 0.97$ & $0.1 \pm 0.49$ \\
LDL-C $(\mathrm{mmol} / \mathrm{l})$ & $-0.6 \pm 0.37^{* * *}$ & $-0.1 \pm 0.86$ & $0.1 \pm 0.22$ \\
HDL-C $(\mathrm{mmol} / \mathrm{l})$ & $0.3 \pm 0.16^{* *}$ & $0.1 \pm 0.24$ & $-0.1 \pm 0.18$ \\
$T G(\mathrm{mmol} / \mathrm{l})$ & $-0.5 \pm 0.51^{* *}$ & $-0.1 \pm 0.80$ & $0.4 \pm 0.52$ \\
\hline
\end{tabular}

Controls - standard spa diet for patients after cardiac surgery; cereal carp group - standard diet enriched by cereal carp; omega-3 carp group - standard diet enriched by omega-3 carp. TC, total cholesterol; LDL-C, low density cholesterol; HDL-C, high density cholesterol; TG, triglycerides. Significantly different from both cereal carp group and controls: $* * p<0.01, * * * p<0.001$.

Table 4. Plasma lipids of three studied groups of patients after 4 weeks of dietary intervention.

\begin{tabular}{lccc}
\hline & Omega-3 carp group & Cereal carp group & Controls \\
\hline$N$ & 37 & 35 & 36 \\
$T C(\mathrm{mmol} / \mathrm{l})$ & $3.9 \pm 0.63^{* *}$ & $4.8 \pm 1.0$ & $5.4 \pm 0.61$ \\
$H D L-C(\mathrm{mmol} / \mathrm{l})$ & $1.2 \pm 0.19^{* *}$ & $1.0 \pm 0.23$ & $0.9 \pm 0.16$ \\
$L D L-C(\mathrm{mmol} / \mathrm{l})$ & $2.0 \pm 0.49^{* *}$ & $2.5 \pm 1.0$ & $2.6 \pm 0.60$ \\
$T G(\mathrm{mmol} / \mathrm{l})$ & $1.5 \pm 0.41^{*}$ & $2.0 \pm 0.81$ & $2.1 \pm 0.60$ \\
\hline
\end{tabular}

Controls - standard spa diet for patients after cardiac surgery; cereal carp group - standard diet enriched by cereal carp; omega-3 carp group - standard diet enriched by omega-3 carp. TC, total cholesterol; LDL-C, low density cholesterol; HDL-C, high density cholesterol; TG, triglycerides. Significantly different from both cereal carp group and controls: $* p<0.05, * * p<0.01$.

The improvement of plasma lipid parameters (a decrease in total cholesterol, LDL cholesterol and triglycerols, and an increase in HDL cholesterol) resulting from the consumption of carp meat, observed by
Adamkova et al. (2011) and in the current study is in agreement with published studies on sea fish (Balk et al. 2006). Fish proteins have been shown to have several positive effects on the different disorders and parameters 
of metabolic syndrome. Among the most important findings observed are anti-inflammatory effects (Calder 2015), increased insulin sensitivity and prevention of type 2 diabetes mellitus (T2DM) and obesity (Lavigne $e t$ al. 2001). Cod protein has been shown to inhibit the development of obesity-linked insulin resistance and glucose intolerance in mice (Lavigne et al. 2000, Lavigne et al. 2001). Similar effects have been observed in human trials (von Post-Skagegård et al. 2006, Ouellet et al. 2007, Ouellet et al. 2008).

However, the mechanisms underlying these effects are to be investigated yet. One of the possible explanations may be high levels of specific amino acids, which contain low levels of branched amino acids, such as taurine and arginine. Calcitonin salmon, the bioactive part of fish protein, has been shown to inhibit osteoporosis (Chesnut et al. 2008) and is a homologue of amylin, a hormone involved in the regulation of satiation and energy expenditure (Osaka et al. 2008).

Pilon et al. (2011) compared the effects of protein in different fish species (bonito, herring, mackerel and salmon) when included in a high-fat, high-sucrose diet fed to rats. They found that, compared with a casein diet, protein from all fish species exhibited anti-inflammatory action through tumor necrosis factor- $\alpha$ and interleukin-6. In addition, the group fed salmon protein had lower weight gain and reduced fat in epididymal white adipose tissue. This suggests that there might be specific effects linked to protein from different fish species. The bioavailability of fatty acids might also differ depending on lipid structure and food matrix (Mu 2008, Schram et al. 2007). The final effect may also symbiotically contribute to other substances in fish.

Recently, there have been many controversies concerning the effects of fatty acids (including omega-3), because inversely risk-related, yet randomized large multicentre trials have not supported this direct relationship (Harris et al. 2016). In one large prospective cohort study of healthy women, intake of tuna, dark fish and marine omega- 3 fatty acids was not associated with the risk of major CVD (Rhee et al. 2017). The National Heart Foundation of Australia recommended that Australian adults should consume $500 \mathrm{mg}$ of omega-3 fatty acids per day for the primary prevention of cardiovascular diseases and $1000 \mathrm{mg}$ of omega-3 fatty acids for the secondary prevention of CVD (Nestel et al. 2015).

The median fish intake at $27 \mathrm{~g} /$ day in all probands showed an inverse association between total fish intake and total mortality among all probands while the association between intake of fish and total mortality was not significant among participants with chronic disease (Villegas et al. 2015). Our probands were given a daily median intake of about $57 \mathrm{~g}$ of fish $(400 \mathrm{~g}$ per week), but only freshwater carp. We have not found any valid trial or study that has focused on carp.

Some recent trials show neutral findings as concerns the effect of long chain fatty acids on the cardiovascular disease event risk. These results may be possibly attributable to e.g. aggressive cardiovascular drug treatment or overshadowing the benefits of these fatty acids (Rice et al. 2016). The current recommendation of American Heart Association for CVD secondary prevention (2011) state that "it may be reasonable to recommend omega-3 fatty acids from fish or fish oil (1 g/day)" (Kleber et al. 2016), but no trials have confirm any significant benefit from intake of these products for reduction of clinical endpoints, while low plasma concentrations of omega- 3 fatty acids precede the development of congestive heart failure (Kleber et al. 2016). As of yet, we have been unable to compare these data with data from our groups. For CVD risk, meta-analyses of randomized controlled trials indicate a significant triglyceride-lowering effect for fish and fish oil. Indeed, recent studies of type 2 diabetics indicate that fish and fish oil may improve endothelial function. Some of the heterogeneity in the results pertaining to fish and fish oil in diabetes may be explained by substantial variation in the experimental designs used, including the selection of study populations, the amount of fish, and fish oil administered, as well as the continually improving standards in healthcare (Ward and Hintze 2016). Compared to the Danish population living in Denmark, diabetes mellitus was essentially unknown among the Inuits (Radcliffe et al. 2016) inhabiting Greenland which forms an autonomous part of the Kingdom of Denmark.

Omega-3 PUFA can attenuate the immune system response of $\mathrm{T}$ cells and macrophages through hitherto unidentified cell surfaces receptors, perhaps by changing the composition of membrane micro-domains, since a recent cross-sectional study on Danish children shows a positive association of mean arterial blood pressure with whole blood DHA (only in boys) (Bonafini et al. 2015). The beneficial effects of $1800 \mathrm{mg} / \mathrm{day}$ of EPA on CVD risk reduction may relate in part to the lowering of Lp-PLA $\mathrm{A}_{2}$ without adversely affecting LDL-C. In contrast, DHA decreases postprandial TG, but raises 
LDL-C. Other observations indicate that these dietary fatty acids have divergent effects on cardiovascular risk markers (Asztalos et al. 2016). Data and analysis were compiled for a prospective cohort study of U.S. women participating in the Women's Health Study (1993-2014). As part of the analysis, the Cox proportional hazards model was used to evaluate the association between fish and energy-adjusted omega-3 polyunsaturated fatty acid intake and the risk of major cardiovascular disease, defined as the composite outcome of myocardial infarction, stroke, and cardiovascular death, in 38.392 women in the final (i.e. $96 \%$ ) analytic sample. There was no modification of effect in age, BMI or baseline history of hypertension differences. In another study a group of women without history of cardiovascular disease, intake of tuna and dark fish, $\alpha$-linolenic acid, and marine omega-3 fatty acids were not associated with the risk of major cardiovascular disease (Rhee et al. 2017).

Another study on normotensive subjects with highest dietary consumption of omega-3 fatty acids had a risk of hypertension development lower by $27 \%$ as compared with subjects with the lowest intake (Colussi et al. 2017).

Patients after myocardial infarction that consumed $1 \mathrm{~g} /$ day of omega-3 PUFA for 3.5 years reduced their mortality rate by $20 \%$ and sudden death rate by $45 \%$ as compared to placebo-administered patients (Harris et al. 2016). Our follow up study is rather short to confirm these results.

Over recent years, a number of observational and intervention studies that have tried to determine the possible cardiovascular protective effects of omega-3 fatty acids have reported negative findings. However, despite these reports the use of fish oil is beneficial for the prevention of sudden death after myocardial infarction, the publication reports an association between supplementation with omega-3 polyunsaturated acids and higher mortality. But while significant results have been obtained regarding the cardioprotective effect of omega-3 PUFA in native Japanese and Alaskan populations, in other population (Americans) the same effect has not been demonstrated (Colussi et al. 2017). A recent report showed the relationship between hypertriglyceridemia and cardiovascular disease, since elevated triglycerides can promote atherogenesis. However, only high-risk patients treated with omega-3 PUFA showed a significant decrease in carotid-femoral pulse wave velocity (Casanova et al. 2016).

It is clear, that further research focused on the intake of polyunsaturated acids and their influence on cardiovascular diseases, comorbidities and mortality must be performed in order to explain their effects.

\section{Conclusion}

In conclusion, we show that carp meat has positive effects on plasma lipids in the secondary prevention of ischemic heart disease. Furthermore, the significance of these effects is strongly influenced by the carp production system. Cardioprotective effects were obtained with the omega-3 carp, which contains five times the amount of EPA+DHA than that of traditional cereal carp. We believe that carp can be of major importance in combating metabolic disorders in many populations in central continental regions without sea access, as carp can be produced world-wide in large quantities. However, more studies - both animal studies and intervention studies on human subjects - are needed to confirm this.

\section{Conflict of Interest}

M.J., P.J. and K.P. are only authors of the Czech Patent nr. 302744, for production of the omega-3 enriched carp. The owner of the patent is the University of South Bohemia in Ceske Budejovice.

\section{Acknowledgements}

This project was supported by Ministry of Health of the Czech Republic Grant No. 16-28352A and by the Project CENAKVA (CZ.1.05/2.1.00/01.0024), CENAKVA II (the results of the project LO1205 were obtained with a financial support from the MEYS under the NPU I program) and by the National Agency for Agricultural Research (QH92307).

\section{References}

ACKMAN RG: Freshwater fish lipids - an overlooked source of beneficial long-chain n-3 fatty acids. Eur J Lipid Sci Technol 104: 253-254, 2002. 
ADAMKOVA V, KACER P, MRAZ J, SUCHANEK P, PICKOVA J, KRALOVA LESNA I, SKIBOVA J, KOZAK P, MARATKA V: The consumption of the carp meat and plasma lipids in secondary prevention in the heart ischemic disease patients. Neuro Endocrinol Lett 32 (Suppl 2): 17-20, 2011.

APPELQVIST LA: Rapid methods of lipid extraction and fatty acid methyl ester preparation for seed and leaf tissue with special remarks on preventing accumulation of lipid contaminants. Arkiv Kemi 28: 551, 1968.

ASZTALOS IB, GLEASON JA, SEVER S, GEDIK R, ASZTALOS BF, HORVATH KV, DANSINGER ML, LAMON-FAVA S, SCHAEFER EJ: Effects of eicosapentaenoic acid and docosahexaenoic acid on cardiovascular disease risk factors: a randomized clinical trial. Metabolism 65: 1636-1645, 2016.

BALK EM, LICHTENSTEIN AH, CHUNG M, KUPELNICK B, CHEW P, LAU J: Effects of omega-3 fatty acids on serum markers of cardiovascular disease risks: a systematic review. Atherosclerosis 18: 19-30, 2006.

BONAFINI S, ANTONIAZZI F, MAFFEIS C, MINUZ P, FAVA C: Beneficial effects of $\omega-3$ PUFA in children on cardiovascular risk factors during childhood and adolescence. Prostaglandins Other Lipid Mediat 120: 72-79, 2015.

CALDER PC: Marine omega-3 fatty acids and inflammatory processes: effects, mechanisms and clinical relevance. Biochim Biophys Acta 1851: 469-484, 2015.

CASANOVA MA, MEDEIROS F, TRINDADE M, COHEN C, OIGMAN W, NEVES MF: Omega-3 fatty acids supplementation improves endothelial function and arterial stiffness in hypertensive patients with hypertriglyceridaemia and high cardiovascular risk. J Am Soc Hypertens in press 2016. doi: 10.1016/ j.jash.2016.10.004

CHESNUT CH, AZRIA M, SILVERMAN S, ENGELHARDT M, OLSON M, MINDEHOLM L: Salmon calcitonin: a review of current and future therapeutic indications. Osteoporos Int 19: 479-491, 2008.

COLUSSI G, CATENA C, NOVELLO M, BERTIN N, SECHI LA: Impact of omega-3 polyunsaturated fatty acids on vascular function and blood pressure. Relevance for cardiovascular outcomes. Nutr Metab Cardiovasc Dis 27: 191-200, 2017.

EFSA: Opinion of the scientific panel on contaminants in the food chain on a request from the European parliament related to the safety assessment of wild and farmed fish. EFSA J 236: 1-118, 2005.

EFSA: Scientific opinion on dietary reference values for fats, including saturated fatty acids, polyunsaturated fatty acids, monounsaturated fatty acids, trans fatty acids, and cholesterol. EFSA J 8: 1461-1568, 2010.

FREDRIKSSON ERIKSSON S, PICKOVA J: Fatty acids and tocopherol levels in M. Longissimus dorsi of beef cattle in Sweden - a comparison between seasonal diets. Meat Science 76: 746-754, 2007.

HARA A, RADIN NS: Lipid extraction of tissues with a low-toxicity solvent. Anal Biochem 90: 420-426, 1978.

HARRIS WS, MASSON S, BARLERA S, MILANI V, PILEGGI S, FRANZOSI MG, MARCHIOLI R, TOGNONI G, TAVAZZI L, LATINI R: Red blood cell acid levels reflect olive oil intake while omega-3 levels reflect fish intake and the use of omega- 3 acid ethyl esters. The Gruppo Italiano per lo Studio della Sopravvivenza nell'Infarto Miocardico-Heart Failure trial. Nutr Res 36: 989-994, 2016.

KLEBER ME, DELGADO GE, LORKOWSKI S, MÄRZ W, VON SCHACKY C: Omega-3 fatty acids and mortality in patients referred for coronary angiography. The Ludwigshafen Risk and Cardiovascular Health Study. Atherosclerosis 25: 175-181, 2016.

LAVIGNE C, MARETTE A, JACQUES H: Cod and soy proteins compared with casein improve glucose tolerance and insulin sensitivity in rats. Am J Physiol Endocrinol Metab 278: E491-E500, 2000.

LAVIGNE C, TREMBLAY F, ASSELIN G, JACQUES HNE, MARETTE A: Prevention of skeletal muscle insulin resistance by dietary cod protein in high fat-fed rats. Am J Physiol Endocrinol Metab 281: E62-E71, 2001.

MRAZ J, PICKOVA J: Differences between lipid content and composition of different parts of fillets from crossbred farmed carp (Cyprinus carpio). Fish Physiol Biochem 35: 615-623, 2009.

MRAZ J, PICKOVA J: Factors influencing fatty acid composition of common carp (Cyprinus carpio) muscle. Neuro Endocrinol Lett 32 (Suppl 2): 3-8, 2011.

MRAZ J, PICKOVA J, KOZAK P: Czech Patent nr. 302744, Feed for common carp and culture of common carp with increased content of omega-3 fatty acids. 2011.

MRAZ J, MACHOVA J, KOZAK P, PICKOVA J: Lipid content and composition in common carp - optimization of n-3 fatty acids in different pond production systems. J Appl Ichthyol 28: 238-244, 2012a. 
MRAZ J, ZAJIC T, PICKOVA J: Culture of common carp (Cyprinus carpio) with defined flesh quality for prevention of cardiovascular diseases using finishing feeding strategy. Neuro Endocrinol Lett 33 (Suppl 2): 60-67, 2012 b.

MU H: Bioavailability of omega-3 long-chain polyunsaturated fatty acids from foods. Agro Food Ind HiTech 19: 24-26, 2008.

NESTEL P, CLIFTON P, COLQUHOUN D, NOAKES M, MORI TA, SULLIVAN D, THOMAS B: Indications for omega-3 long chain polyunsaturated fatty acid in the prevention and treatment of cardiovascular disease. Heart Lung Circ 24: 769-779, 2015.

OSAKA T, TSUKAMOTO A, KOYAMA Y, INOUE S: Central and peripheral administration of amylin induces energy expenditure in anesthetized rats. Peptides 29: 1028-1035, 2008.

OUELLET V, MAROIS J, WEISNAGEL SJ, JACQUES H: Dietary cod protein improves insulin sensitivity in insulin-resistant men and women: a randomized controlled trial. Diabet Care 30: 2816-2821, 2007.

OUELLET V, WEISNAGEL SJ, MAROIS J, BERGERON J, JULIEN P, GOUGEON R, TCHERNOF A, HOLUB BJ, JACQUES H: Dietary cod protein reduces plasma C-reactive protein in insulin-resistant men and women. J Nutr 138: 2386-2391, 2008.

PAULETTO P, PUATO M, CAROLI MG, CASIGLIA E, MUNHAMBO AE, CAZZOLATO G, BON GB, ANGELI MT, GALLI C, PESSINA AC: Blood pressure and atherogenic lipoprotein profiles of fish-diet and vegetarian villagers in Tanzania: The Lugalawa study. Lancet 348: 784-788, 1996.

PILON G, RUZZIN J, RIOUX LE, LAVIGNE C, WHITE PJ, FRØYLAND L, JACQUES H, BRYL P, BEAULIEU L, MARETTE A: Differential effects of various fish proteins in altering body weight, adiposity, inflammatory status, and insulin sensitivity in high-fat-fed rats. Metabolism 60: 1122-1130, 2011.

RADCLIFFE JE, THOMAS J, BRAMLEY AL, KOURIS-BLAZOS A, RADFORD BE, SCHOLEY AB, PIPINGAS A, THOMAS CJ, ITSIOPOULOS C: Controversies in omega-3 efficacy and novel concepts for application. J Nutrit Intermed Metabol 5: 11-22, 2016.

RHEE JJ, KIM E, BURING JE, KURTH T: Fish consumption, omega-3 fatty acids, and risk of cardiovascular disease. Am J Prev Med 52: 10-19, 2017.

RICE HB, BERNASCONI A, MAKI KC, HARRIS WS, VON SCHACKY C, CALDER PC: Conducting omega-3 clinical trials with cardiovascular outcomes: Proceedings of a workshop held at ISSFAL 2014. Prostaglandins Leukot Essent Fatty Acids 107: 30-42, 2016.

SAMPELS S, ZAJIC T, MRAZ J: Effects of frying fat and preparation on carp (Cyprinus carpio) fillet lipid composition and oxidation. Czech J Food Sci 32: 493-502, 2014.

SAMPELS S, ZAJIC T, MRAZ J: Increasing the omega-3 content of traditional meat products by the addition of an underutilized by-product from fish processing. Czech J Food Sci 33: 431-440, 2015.

SCHRAM LB, NIELSEN CJ, PORSGAARD T, NIELSEN NS, HOLM R, MU H: Food matrices affect the bioavailability of (n-3) polyunsaturated fatty acids in a single meal study in humans. Food Res Int 40: 1062-1068, 2007.

ÚZEI: Annual report 2015. ÚZEI, 2016, p. 75, ISBN 978-80-7271-219-9.

VILLEGAS R, TAKATA Y, MURFF H, BLOT WJ: Fish, omega-3 long chain fatty acids, and all-cause mortality in a low-income US population: results from the Southern Community Cohort Study. Nutr Metab Cardiovasc Dis 5: 651-658, 2015.

VON POST-SKAGEGÅRD M, VESSBY B, KARLSTRÖM B: Glucose and insulin responses in healthy women after intake of composite meals containing cod-, milk-, and soy protein. Eur J Clin Nutr 60: 949-954, 2006.

WARD R, HINTZE K: Fish and Fish Oil, Health and Disease Prevention. Elsevier, London, 2016, p. $217-229$.

ZAJIC T, MRAZ J, SAMPELS S, PICKOVA J: Fillet quality changes as a result of purging of common carp (Cyprinus carpio L.) with special regard to weight loss and lipid profile. Aquaculture 400: 111-119, 2013.

ZENISKOVA H, GALL V: Situational and Prospective Report, Fish (in Czech). Ministry of Agriculture, Prague, 2009, pp 1-46. ISBN 978-80-7084-806-7, ISSN 1211-7692. 